\title{
ANALISISREAL TIME RUGI-RUGI AKIBAT KETIDAKSEIMBANGAN PEMBEBANAN PADA TRAFO BERBASIS LABVIEW
}

\author{
Agus setiawan \\ Jurusan Teknik Elektro FT UNPAM \\ Citra Raya,Cluster Green Sevilla V05/57, Tangerang 15610 INDONESIA \\ dosen00935@unpam.ac.id
}

\begin{abstract}
ABSTRAK
Ketidakseimbangan beban pada sistem 3 fasa menyebabkan mengalirnya arus di netral trafo, dan dengan adanya rugi belitan dan rugi inti besi menambah rugi-rugi menjadi semakin besar sehingga efisiensi trafo akan semakin rendah. Oleh karena itu penelitian ini menjadi sangat penting dilakukan untuk mengetahui rugi-rugi pada trafo secara real time. Tujuan penelitian ini untuk mengetahui rugi-rugi trafo secara real time dengan membuat suatu sistem akuisisi data yang digunakan untuk analisis rugi-rugi yang diakibatkan oleh ketidakseimbangan pembebanan pada trafo berbasis labview. Penelitian ini menggunakan metode pengukuran langsung terhadap trafo yang menjadi objek penelitian dilengkapi trafo arus dan trafo tegangan sebagai sensor pendeteksi arus dan tegangan yang dihubungkan dengan sistem akuisisi data berbasis labview. Hasil yang diperoleh dalam penelitian ini adalah sistem akuisisi data program labview yang menunjukan total rugi-rugi pada beban seimbang 191,14 Watt, efisiensi 55,06\%, arus netral yang muncul 0,0392 A, faktor ketidakseimbangan $\mathrm{K} 14,16 \%$, beban tidak seimbang model $\mathrm{A}$ total rugi-rugi 186,24 Watt, efisiensi $54,36 \%$, arus netral yang muncul $0,1986 \mathrm{~A}$, faktor ketidakseimbangan $\mathrm{K} 46,36 \%$, beban tidak seimbang model B total rugi-rugi 192,77 Watt efisiensi $53,89 \%$ arus netral yang muncul 0,2202 A, faktor ketidakseimbangan $\mathrm{K} 49,76 \%$. Dapat disimpulkan berdasarkan hasil penelitian menujukan sistem yang telah dibuat dapat digunakan untuk analisis real time rugi-rugi trafo dan menunjukan bahwa beban tidak seimbang menyebabkan efisiensi trafo semakin kecil dan rugi-rugi pada arus netral semakin besar.
\end{abstract}

Kata kunci : ketidakseimbangan, rugi-rugi, real time, labview, trafo, efisiensi.

\begin{abstract}
Load imbalance on the 3 phase system causes the flow of current in the transformer neutral, and with the loss of winding and loss of iron core increases losses become greater so that the transformer efficiency will be lower. Therefore, this research is very important to be carried out to determine the losses in the transformer in real time. The purpose of this study is to determine transformer losses in real time by making a data acquisition system that is used for loss analysis due to the imbalance of loading on labview-based transformers. This study uses a direct measurement method of transformer which is the object of research equipped with current transformers and voltage transformers as current and voltage detection sensors that are connected with labview based data acquisition systems. The results obtained in this study is the labview program data acquisition system which shows the total losses in a balanced load of 191.14 Watts, $55.06 \%$ efficiency, neutral currents that appear 0.0392 A, K imbalance factor $14.16 \%$, load unbalanced model A total losses 186.24 Watts, efficiency 54.36\%, neutral currents that appear 0.1986 A, K imbalance factor $46.36 \%$, unbalanced load model B total losses 192.77 Watt efficiency $53.89 \%$ of neutral currents that appear $0.2202 \mathrm{~A}, \mathrm{~K}$ imbalance factor $49.76 \%$. It can be concluded based on the results of the research addressing the system that has been made can be used for real time analysis of transformer losses and shows that unbalanced loads cause smaller transformer efficiency and greater losses in neutral currents.
\end{abstract}

Keywords : imbalances, losses, real time, labview, transformer, efficiency. 


\section{PENDAHULUAN}

$\mathrm{D}$ alam menjaga stabilitas sistem tenaga listrik, kualitas daya merupakan hal yang penting, karenanya untuk menjaga stabilitas tersebut perlu diperhatikan pembebanan pada transformator. Ketidakseimbangan beban antara tiap-tiap fasa (fasa $R$, fasa $S$, dan fasa $T$ ) menyebabkan mengalirnya arus di netral trafo yang merupakan rugi-rugi, dengan adanya rugi belitan dan rugi inti besi menambah rugi-rugi menjadi semakin besar dan efisiensi trafo akan semakin rendah. Semakin besar faktor ketidakseimbangan maka akan semakin besar arus netral yang muncul. Oleh karena itu penelitian ini menjadi sangat penting dilakukan untuk mengetahui rugi-rugi trafo secara real time. Tujuan penelitian ini untuk mengetahui rugirugi trafo secara real time dengan membuat suatu sistem akuisisi data yang digunakan untuk analisis rugi-rugi yang diakibatkan oleh ketidakseimbangan pembebanan pada trafo berbasis labview yang memberikan hasil analisis yang akurat dan visualisasi yang informatif. Penelitian ini menggunakan metode pengukuran langsung terhadap trafo yang menjadi objek penelitian dilengkapi trafo arus dan trafo tegangan sebagai sensor pendeteksi arus dan tegangan yang dihubungkan dengan sistem akuisisi data berbasis labview.

\section{LANDASAN TEORI}

\section{Rugi-Rugi Transformator}

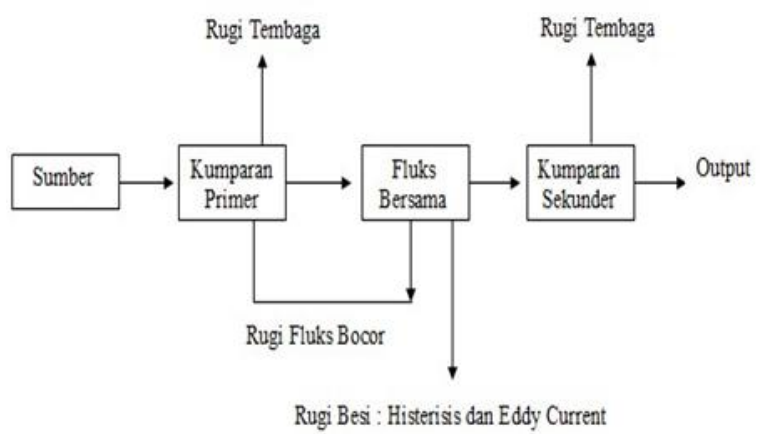

Gambar 1. Rugi-rugi transformator

a. Rugi Tembaga (Pcu)

Rugi tembaga adalah rugi yang disebabkan arus beban yang mengalir pada kawat tembaga dapat ditulis sebagai berikut: $\mathrm{Pcu}=\mathrm{I}^{2} \times \mathrm{R}$ Dimana:
$\mathrm{R}=$ Tahanan pengganti (Ohm)

$\mathrm{I}^{2}=$ Arus yang mengalir disisi sekunder

(Ampere)

$\mathrm{Pcu}=$ Rugi tembaga(Watt)

b. Rugi Besi (Pi)

Rugi besi terdiri atas :

1. Rugi hysteresis yaitu rugi yang disebabkan fluks bolak-balik pada inti besi. Rugi hysterisis terjadi karena respon yang lambat dari material inti. Hal ini terjadi karena masih adanya medan magnetik residu yang bekerja pada material, jadi saat arus eksitasi bernilai 0 , fluks tidak serta merta berubah menjadi 0 namun perlahan-lahan menuju 0 . Sebelum fluks mencapai nilai 0 arus sudah mulai mengalir kembali atau dengan kata lain arus sudah bernilai tidak sama dengan sehingga akan membangkitkan fluks kembali [2].

2. Rugi arus eddy merupakanrugi yang disebabkan arus pusar pada inti besi. Arus pusar adalah arus yang mengalir pada material inti karena tegangan yang diinduksi oleh fluks. Arah pergerakan arus pusar adalah $90^{\circ}$ terhadap arah fluks. Dengan adanya resistansi dari material inti maka arus pusar dapat menimbulkan panas sehingga mempengaruhi sifat fisik material inti tersebut bahkan hingga membuat transformator terbakar. Untuk mengurangi efek arus pusar maka material inti harus dibuat tipis dan dilaminasi sehingga dapat disusun hingga sesuai tebal yang diperlukan [2].Arus eddy yaitu arus listrik dalam konduktor yang diinduksi oleh medan magnet yang berubah-ubah. yang disebabkan oleh perputaran beberapa arus transien dalam koil, elektromagnet atau transformator. Besarnya arus induksi sebanding dengan kekuatan medan magnet dan laju perubahan fluks [3].

\section{Ketidakseimbangan Beban [4]}

Yang dimaksud dengan keadaan seimbang adalah suatu keadaan dimana :

- Ketiga vektor arus / tegangan adalah sama besar

- Ketiga vektor saling membentuk sudut $120^{\circ}$ satu sama lain

Sedangkan yang dimaksud dengan keadaan tidak seimbang adalah keadaan dimana salah satu atau kedua syarat keadaan seimbang tidak terpenuhi. 
Kemungkinan keadaan tidak seimbang ada tiga yaitu :

- Ketiga vektor sama besar tetapi tidak membentuk sudut $120^{\circ}$ satu sama lain

- Ketiga vektor tidak sama besar tetapi membentuk sudut $120^{\circ}$ satu sama lain

- Ketiga vektor tidak sama besar dan tidak membentuk sudut $120^{\circ}$ satu sama lain.

Di sini terlihat bahwa penjumlahan ketiga vektor arusnya (IR, IS, IT) adalah tidak sama dengan nol sehingga muncul suatu besaran yaitu arus netral (IN) yang besarnya bergantung pada seberapa besar faktor ketidakseimbangannya.

\section{Arus Netral Karena Beban Tidak Seimbang}

Dalam sistem tiga fase, arus netral adalah penjumlahan dari tiga fase arus. Pada beban seimbangan dan beban resistif, tiga arus memiliki nilai yang sama tetapi berbeda $120^{\circ}$ masing-masing fase, sehingga jumlah dari tiga fase arus netral akan menjadi nol. Ini dapat membantu menyediakan kabel netral pada sistem empat atau lima kawat, di mana yang kabel netral bisa sangat kecil atau dihilangkan pada sistem tiga kawat. Namun, kondisi ini sulit untuk dilakukan mencapai pada aplikasi nyata. Arus beban akan tergantung pada permintaan beban / perilaku konsumen yang cenderung beban yang induktif [5]. Untuk arus tiga fasa dari suatu sistem yang tidak seimbang dapat juga diselesaikan dengan menggunakan metode komponen simetris. Tiga fasor tak seimbang dari sistem tiga fasa dapat diuraikan menjadi tiga fasor yang seimbang.

- Komponen urutan positif (positive components) yang terdiri dari tiga fasor yang sama besarnya, terpisah satu dengan yang lain dalam fasa sebesar $120^{\circ}$, dan mempunyai urutan fasa yang sama seperti fasor aslinya (abc).

- Komponen urutan negatif yang terdiri dari fasor yang sama besarnya, terpisah satu dengan yang lain dalam fasa sebesar $120^{\circ}$, dan mempunyai urutan fasa yang berlawanan dengan fasor aslinya (acb).

- Komponen urutan nol yang terdiri dari tiga fasor yang sama besarnya dan dengan pergeseran fasa nol antara yang satu dengan yang lain.
Dengan menggunakan notasi-notasi yang sama seperti pada tegangan akan didapatkan persamaan-persamaan untuk arus-arus fasanya sebagai berikut :
$\mathrm{la}=\mathrm{I}_{1}+\mathrm{I}_{2}+\mathrm{I}_{0}$
$\mathrm{lb}=\mathrm{a}_{2} \mathrm{l}_{1}+\mathrm{al} \mathrm{I}_{2}+\mathrm{I}_{0}$
$\mathrm{lc}=\mathrm{al}_{1}+\mathrm{a}_{2} \mathrm{I}_{2}+\mathrm{I}_{0}$

Dengan tiga langkah yang telah dijabarkan dalam menentukan tegangan urutan positif, urutan negatif, dan urutan nol terdahulu, maka arus-arus urutan juga dapat ditentukan dengan cara yang sama, sehingga kita dapatkan juga :

$$
\begin{aligned}
& I_{1}=1 / 3\left(l a+a l b+a_{2} l c\right) \\
& I_{2}=1 / 3\left(l a+a_{2} l b+a l c\right) \\
& I_{0}=1 / 3(l a+l b+l c)
\end{aligned}
$$

Di sini terlihat bahwa arus urutan nol $\left(\mathrm{I}_{0}\right)$ adalah merupakan sepertiga dari arus netral atau sebaliknya akan menjadi nol jika dalam sistem tiga fasa empat kawat. Dalam sistem tiga fasa empat kawat ini jumlah arus saluran sama dengan arus netral yang kembali lewat kawat netral, menjadi :

$\mathrm{IN}=\mathrm{la}+\mathrm{lb}+\mathrm{lc}$

Dengan mensubstitusikan persamaan maka diperoleh :

IN =3 I

Dalam sistem tiga fasa empat kawat ini jumlah arus dalam saluran sama dengan arus netral yang kembali lewat kawat netral. Jika arus-arus fasanya seimbang maka arus netralnya akan bernilai nol, tapi jika arusarus fasanya tidak seimbang, maka akan ada arus yang mengalir di kawat netral sistem (arus netral akan mempunyai nilai dalam arti tidak nol).

\section{Faktor Daya (Cos Phi)}

Istilah Power Factor (PF)telah muncul dengan meningkatnya konsumsi daya reaktif dalam sistem distribusi listrik. Istilah ini digunakan untuk menyatakan seberapa efektif energi listrik diubah menjadi bentuk yang bermanfaat dan secara bersamaan menunjukkan kualitas layanan ke pemberi layanan listrikdan pengguna akhir. PF adalah rasio antara daya aktif $(P)$ dan daya semu (S) [6]. Ini juga didefinisikan sebagai nilai kosinus dari Phase Difference (PD) antara tegangan (V) dan arus (I) dari sistem tenaga listrik AC. Dirumuskan sebagai berikut :

$\mathrm{PF}=\operatorname{Cos}(\phi)=\mathrm{P} / \mathrm{S}$

dimana $(\phi)$ adalah nilai sudut PD antara dua sinyal sinusoidal. 


\section{Pengkajian Akuisisi Data LabVIEW [7] LabVIEW dirancang untuk} memantau, dan menghitung rugi-rugi trafo secara real-time. Perangkat lunak LabVIEW ini dirancang untuk mendeteksi perbedaan fase antara pulsa berturut-turut dan menghasilkan umpan balik yang sesuai. Akuisisi data dan tampilan gelombang arus dan tegangan dengan opsi penyimpanan data real-time juga ditambahkan. Umpan balik tegangan dan arus menampilkan grafik yang dipantau dalam perangkat lunak LabVIEW ini yang menunjukkan perkiraan nilai level tegangan dan arus pada keluaran, juga menampilkan nilai-nilai hasil formulasi yang dibutuhkan. Front panel perangkat lunak yang dirancang ditunjukkan pada Gambar. 3, 4 dan 5.

\section{METODOLOGI}

\section{Bahan Dan Alat Penelitian}

Objek yang akan diteliti pada penelitian ini adalah trafo 3 fasa yang ada di laboratorium universitas pamulang dengan spesifikasi kapasitas $421 \mathrm{VA}$, nilai resistansi sisi primer fasa R,S,T 41 ohm dan sisi sekunder resistansi fasa $R 70,5 \mathrm{ohm}$, fasa $S$ $69,5 \mathrm{ohm}$ dan fasa $\mathrm{T}$ 69,7 ohm, dengan beban lampu pijar $100 \mathrm{~W} 1$ buah, 75 W 3 buah, dan $25 \mathrm{~W} 2$ buah. Bahan-bahan yang diperlukan dalam penelitian ini meliputi bahan-bahan software dan hardware, untuk software yang digunakan adalah labview versi 201332 bit dan hardware yang digunakan yaitu NI USB 6009, CT type $\mathrm{BH}$ $0.66 \mathrm{CT}$, VT step down 220 volt ke 3 volt.Sistem aquisisi data yang dibuat dan digunakan untuk analisis rugi-rugi real time akibat ketidakseimbangan pembebanan pada trafo berbasis labview dapat dilihat seperti gambar 2 .

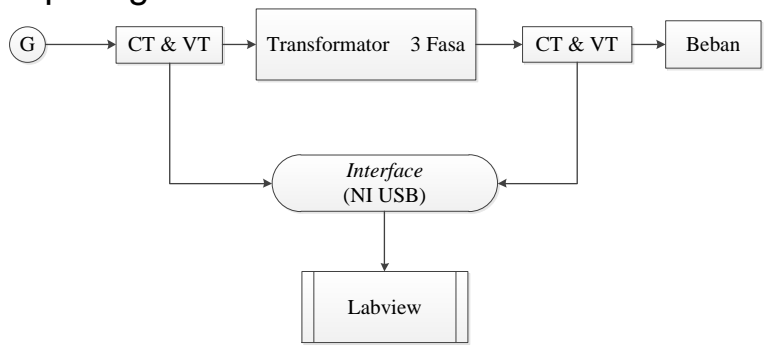

Gambar 2. Blok diagram sistem
Pada gambar dapat kita lihat proses kerja dari sistem yang digunakan untuk aquisisi data adalah sebagai berikut :

a. Trafo sisi primer dihubungkan langsung ke sumber listrik 3 fasa dan sisi sekunder dihubungkan dengan beban.

b. Pengukuran dilakukan terhadap trafo dengan beban yang seimbang dan tidak seimbang, dengan total daya beban sama antara keadaan seimbang dan tidak seimbang.

c. Pada sisi primer dan sisi sekunder trafo dipasangkan trafo arus (CT) dan trafo tegangan (VT) pada masing-masing fasanya.

d. Trafo arus (CT) dan trafo tegangan (VT) dihubungkan langsung ke perangkat sebagai interface yaitu NI USB 6009.

e. NI USB akan membaca sinyal analog yang masuk dari CT dan VT.

f. NI USB dihubungkan dengan PC/laptop yang telah terinstal perangkat lunak labview

g. Labview akan menampilkan hasil pembacaan sinyal analog dari NI USB dan diolah berdasarkan program yang dibuat.

Semua informasi yang diperlukan dan digunakan dalam peneltian ini dapat ditampilkan langsung pada front panel labview yang telah disesuaikan desain tampilannya.

\section{HASIL DAN PEMBAHASAN}

\section{Hasil Pengukuran}

Tabel 1. Data teknis trafo dan pembebanan

\begin{tabular}{|c|c|c|c|c|c|}
\hline \multicolumn{3}{|c|}{ Data Teknis Trafo } & \multirow{2}{*}{\begin{tabular}{|c|} 
Beban \\
seimbang \\
Watt
\end{tabular}} & \multirow{2}{*}{$\begin{array}{c}\text { Beban tidak } \\
\text { seimbang } \\
\text { model A }\end{array}$} & \multirow{2}{*}{$\begin{array}{c}\text { Beban tidak } \\
\text { seimbang } \\
\text { model B } \\
\text { Watt }\end{array}$} \\
\hline Resistansi & Primer & Sekunder & & & \\
\hline $\mathrm{R}$ & $41 \mathrm{ohm}$ & $70.5 \mathrm{ohm}$ & 75 & 100 & 50 \\
\hline $\mathrm{S}$ & $41 \mathrm{ohm}$ & $69.5 \mathrm{ohm}$ & 75 & 75 & 75 \\
\hline $\mathrm{T}$ & $41 \mathrm{ohm}$ & $69.7 \mathrm{ohm}$ & 75 & 50 & 100 \\
\hline
\end{tabular}

Dalam pelaksanaan pengukuran parameter-parameter yang nilainya bisa didapatkan dengan hanya bermodalkan gelombang arus dan tegangan diantaranya nilai tegangan dan sudutnya, nilai arus dan sudutnya, daya rata-rata, rugi-rugi cu, total daya, rugi-rugi besi, total rugi-rugi, efisiensi, daya semu, cos phi, arus urutan nol ( $\mathrm{ia}_{0}$ ), arus urutan positif $\left(\mathrm{ia}_{1}\right)$, arus urutan negatif $\left(\mathrm{ia}_{2}\right)$ dan ketidakseimbangan (K). 


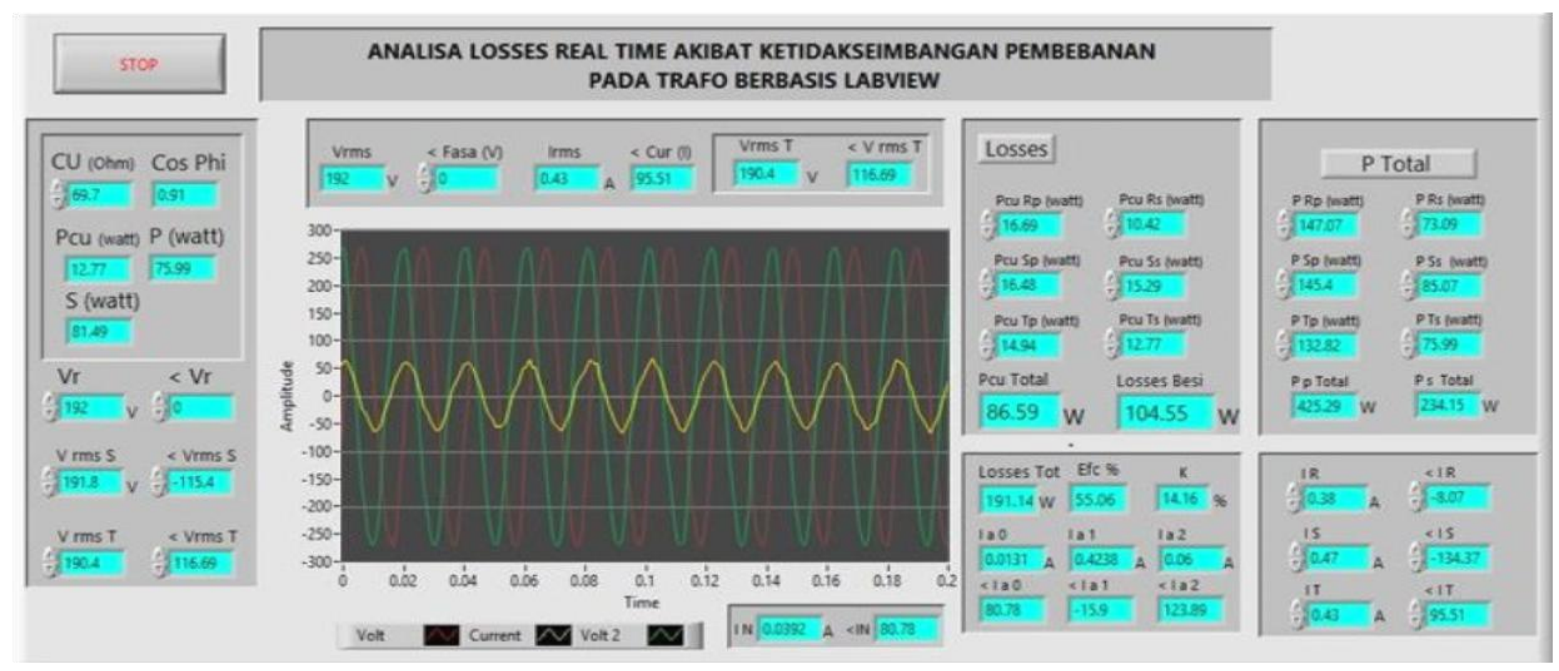

Gambar 3. Screenshoot labview hasil pengukuran pada beban seimbang

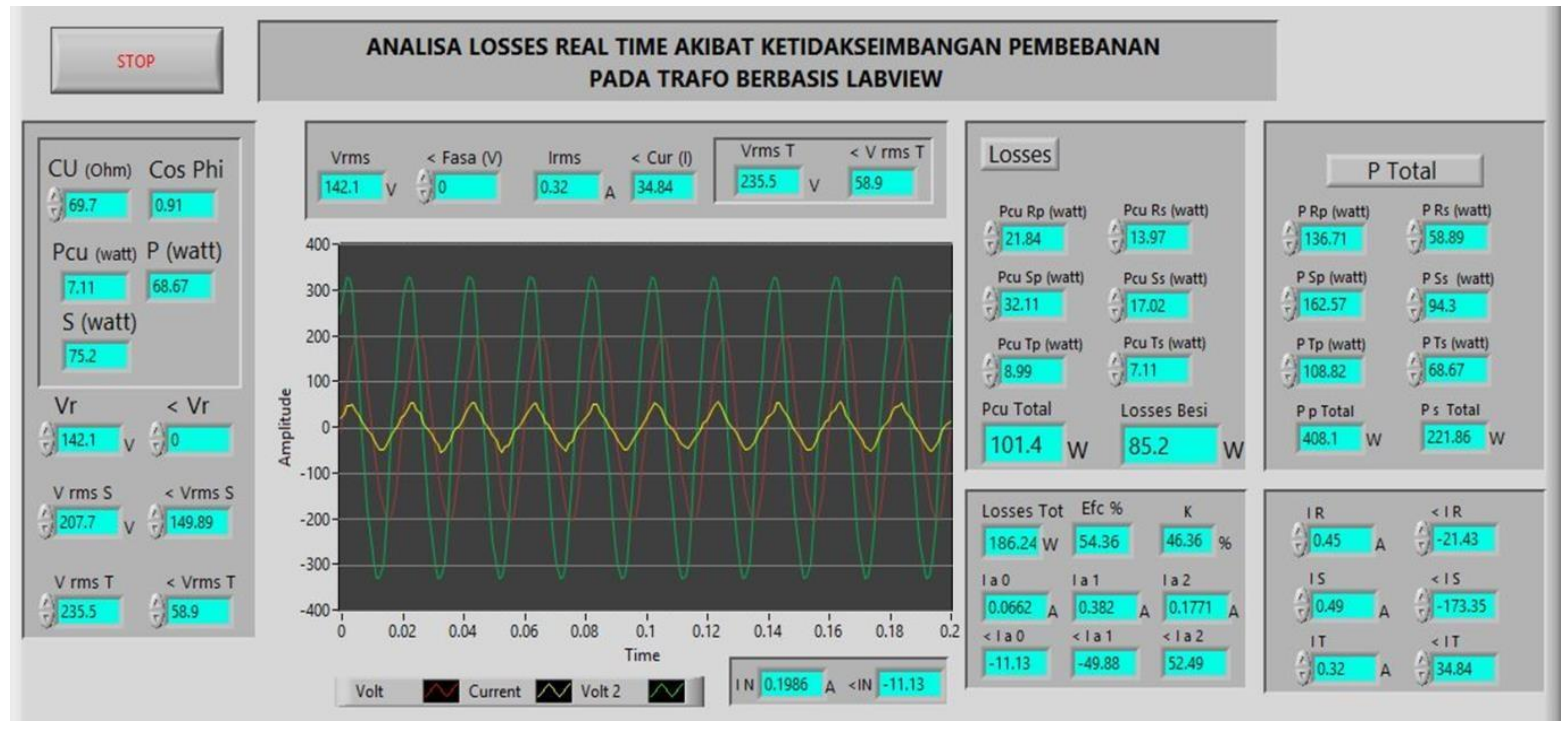

Gambar 4. Screenshoot labview hasil pengukuran pada beban tidak seimbang konfigurasi A

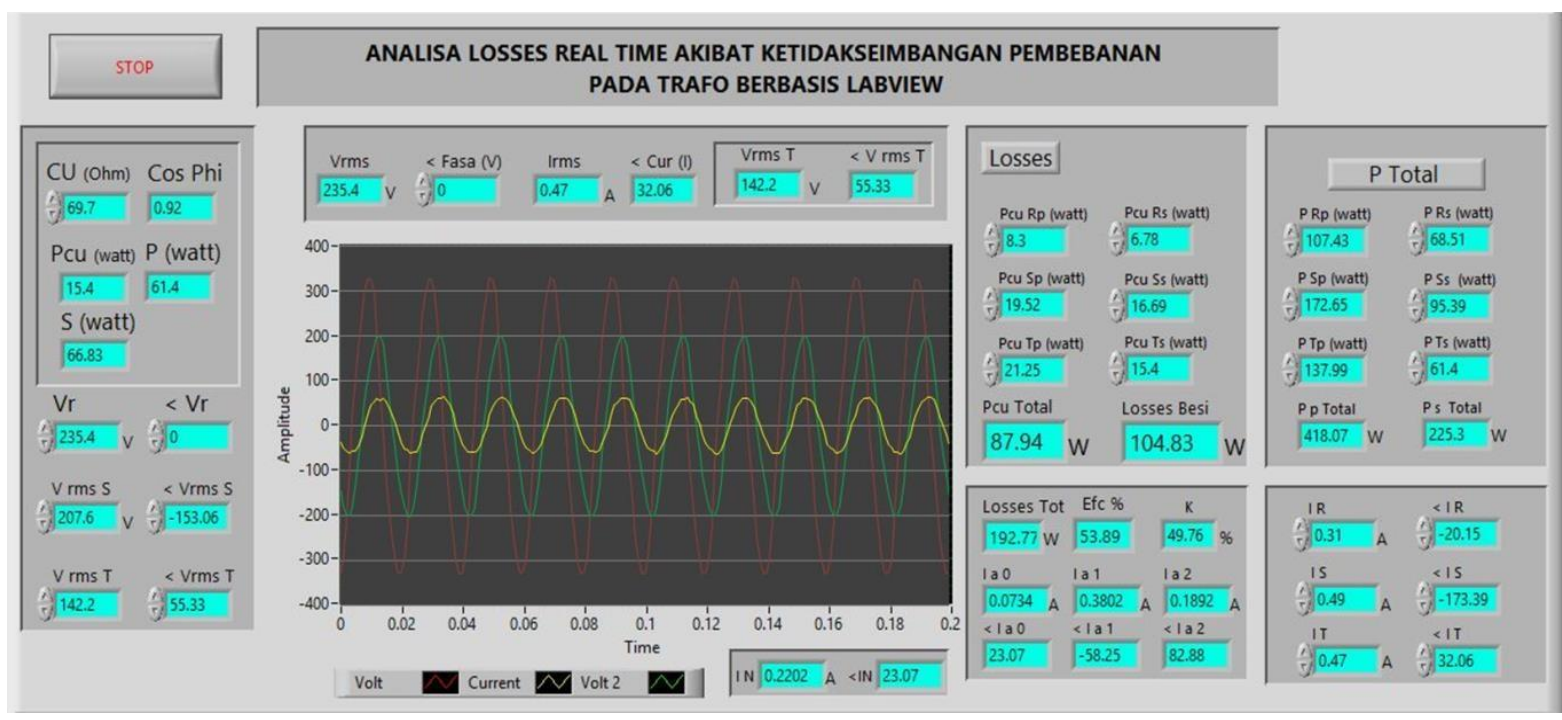

Gambar 5. Screenshoot labview hasil pengukuran pada beban tidak seimbang konfigurasi B 


\section{ANALISIS DATA PADA BEBAN SEIMBANG \\ Sisi Primer Trafo \\ Diketahui : \\ Tegangan fasa $\mathrm{R}: 237,3 \angle 0^{\circ}$ Volt

$$
\begin{aligned}
& S: 240,3 \text { Volt } \\
& T \text { : } 232,7 \text { Volt }
\end{aligned}
$$

Arus fasa $R: 0,64$ Ampere

$$
\begin{aligned}
& \mathrm{S}: 0,63 \text { Ampere } \\
& \mathrm{T}: 0,60 \text { Ampere }
\end{aligned}
$$

Daya aktif Fasa R : 147,07 Watt

$$
\begin{aligned}
& S: 145,4 \text { Watt } \\
& T: 132,82 \text { Watt }
\end{aligned}
$$

Dihitung :

Rugi-rugi CU fasa $R=16,69$ Watt

Rugi-rugiCU fasa $S=16,48$ Watt

Rugi-rugi CU fasa $T=14,94$ Watt

Total rugi-rugi CU primer $=48,11$ Watt

Total daya aktif primer $=425,29$ Watt

Daya semu fasa $S_{R}=151,40 \mathrm{VA}$

Daya semu fasa $S_{S}=152,35 \mathrm{VA}$

Daya semu fasa $S_{T}=140.48$ VA

Cos Phi fasa $R=0.97$

Cos Phi fasa $S=0.95$

Cos Phi fasa $T=0.95$

Sudut fasa tegangan $R=V r=\angle 0^{\circ}$. Sudut fasa tegangan $S=V s=116,45^{\circ}$. Karena $\angle$ fasa $\mathrm{Vr}$ sebagai acuan bernilai $0^{\circ}$ dan sudut fasa Vs bersifat lagging maka, sudut fasa $S=0^{\circ}-116,45^{\circ}=\angle-116,45^{\circ}$. Sudut fasa tegangan $\mathrm{T}=\mathrm{Vt}=$ $123,39^{\circ}$.Karena $\angle$ fasa $\operatorname{Vr}$ sebagai acuan bernilai $0^{\circ}$ dan sudut fasa $\mathrm{Vt}$ bersifat leading maka sudut fasa $\mathrm{T}=0^{\circ}+123,39^{\circ}=$ $\angle 123,39^{\circ}$. Sudut arus fasa $R=13.74^{\circ}$ Karena $\angle$ fasa $V_{\mathrm{R}}$ sebagai acuan bernilai $0^{\circ}$ dan sudut fasa bersifat lagging maka sudut arus fasa $R=0^{\circ}-13,74^{\circ}=\angle-13.74^{\circ}$. Sudut arus fasa $S=17,38^{\circ}$. Karena $\angle$ fasa $V_{S}$ sebagai acuan bernilai $-116,45^{\circ}$ dan sudut fasa bersifat lagging maka sudut arus fasa $\mathrm{S}=$ $116,45^{\circ}-17,38^{\circ}=\angle-133,83^{\circ}$. Sudut arus fasa $\mathrm{T}=19,01^{\circ}$. Karena $\angle$ fasa $\mathrm{V}_{\mathrm{T}}$ sebagai acuan bernilai $123,39^{\circ}$ dan sudut fasa bersifat lagging maka sudut arus fasa $\mathrm{T}=$ $123,39^{\circ}-19,01^{\circ}=\angle 104,37^{\circ}$

\section{Sisi Sekunder Trafo}

Diketahui :

Tegangan fasa $\mathrm{R}: 192 \angle 0^{\circ}$ volt

$$
S: 191,8 \text { volt }
$$

$$
\mathrm{T}: 190,4 \text { volt }
$$

Arus fasa $\mathrm{R}: 0,38$ Ampere

$$
S: 0,47 \text { Ampere }
$$

$\mathrm{T}: 0,43$ Ampere

Daya aktif Fasa R : 73.09 Watt

$$
\begin{aligned}
& S: 85.07 \text { Watt } \\
& \mathrm{T}: 75,99 \text { Watt }
\end{aligned}
$$

Dihitung

Rugi-rugi CU fasa $R=10,42$ Watt

Rugi-rugi CU fasa $S=15,29$ Watt

Rugi-rugi CU fasa $T=12,77$ Watt

Total rugi-rugi CU sekunder $=38,48 \mathrm{Watt}$

Total daya aktif sekunder $=234,15$ Watt

Daya semu fasa $S_{R}=73,82 \mathrm{VA}$

Daya semu fasa $S_{S}=89,95 \mathrm{VA}$

Daya semu fasa $S_{T}=81,49 \mathrm{VA}$

Cos Phi fasa $R=0.99$

Cos Phi fasa $S=0.95$

Cos Phi fasa $T=0.93$

Sudut fasa tegangan $\mathrm{R}=\mathrm{Vr}=\angle 0^{\circ}$

Sudut fasa tegangan $\mathrm{S}=\mathrm{Vs}=115,4^{\circ}$

Karena $\angle$ fasa $\mathrm{Vr}$ sebagai acuan bernilai $0^{\circ}$ dan sudut fasa Vs bersifat lagging maka sudut fasa $S=0^{\circ}-115,4^{\circ}=\angle-115,4^{\circ}$. Sudut fasa tegangan $\mathrm{T}=116,69^{\circ}$. Karena $\angle$ fasa $\mathrm{Vr}$ sebagai acuan bernilai $0^{\circ}$ dan sudut fasa Vt bersifat leading maka sudut fasa $\mathrm{T}=0^{\circ}+$ $116,69^{\circ}=\angle 116,69^{\circ}$. Sudut arus fasa $R=$ $8,07^{\circ}$. Karena $\angle$ fasa $V_{R}$ sebagai acuan bernilai $0^{\circ}$ dan sudut fasa bersifat lagging maka sudut arus fasa $R=0^{\circ}-8,07^{\circ}=\angle-$ $8,07^{\circ}$. Sudut arus fasa $\mathrm{S}=18,97^{\circ}$. Karena $\angle$ fasa $V_{S}$ sebagai acuan bernilai $-115,4^{\circ}$ dan sudut fasa bersifat lagging maka sudut arus fasa $S=-115,4^{\circ}-18,97^{\circ}=\angle-134,37^{\circ}$. Sudut arus fasa $\mathrm{T}=21,18^{\circ}$. Karena $\angle$ fasa $\mathrm{V}_{\mathrm{T}}$ sebagai acuan bernilai $116,69^{\circ}$ dan sudut fasa bersifat lagging maka sudut arus fasa $T$ $=116,69^{\circ}-21,18^{\circ}=\angle 95,51^{\circ}$

Total rugi-rugi trafo $=191,14$ Watt

Total rugi-rugi $\mathrm{CU}=86,59 \mathrm{Watt}$

Rugi-rugi inti besi $=104,55$ Watt

Efisiensi trafo $=55,06 \%$

Untuk mendapatkan nilai arus netral pada beban seimbang dan tidak seimbang adalah dengan menggunakan metode komponen simetris Dengan menentukan arus urutan nol, arus urutan positif dan arus urutan negatif. Arus-arus urutan pada beban seimbang :

- Arus urutan 0 (nol)

$\mathrm{la}_{0}=\frac{1}{3}\left(\mathrm{I}_{\mathrm{R}}+\mathrm{I}_{\mathrm{S}}+\mathrm{I}_{\mathrm{T}}\right)$ 


$$
=0.0131 \angle 80,78^{\circ} \mathrm{A}
$$

- Arus urutan positif

$\mathrm{Ia}_{1}=\frac{1}{3}\left(\mathrm{I}_{\mathrm{R}}+\mathrm{al}_{\mathrm{S}}+\mathrm{a}^{2} \mathrm{I}_{\mathrm{T}}\right)$

$=0.4238 \angle-15,9^{\circ} \mathrm{A}$

- Arus urutan negatif

$\mathrm{Ia}_{2}=\frac{1}{3}\left(\mathrm{I}_{\mathrm{R}}+\mathrm{a}^{2} \mathrm{I}_{\mathrm{S}}+\mathrm{a} \mathrm{I}_{\mathrm{T}}\right)$

$=0.06 \angle 123,89^{\circ} \mathrm{A}$
$\mathrm{I}_{\mathrm{N}}=3 \times \mathrm{Ia}_{0}=0.0392 \angle 80,78^{\circ}$

$K=\frac{l a_{2}}{l a_{1}} \times 100 \%=14,16 \%$

Untuk beban tidak seimbang model $A$ dan model $B$ dengan metode hitung yang sama dapat diperoleh nilai-nilai yang terdapat dalam tabel berikut ini

Tabel 2. Hasil perhitungan pada beban tidak seimbang model A dan model $B$

\begin{tabular}{|c|c|c|c|c|c|c|c|c|c|c|c|c|c|}
\hline \multirow{2}{*}{\multicolumn{2}{|c|}{$\begin{array}{c}\text { Parameter } \\
\text { Fasa }\end{array}$}} & \multicolumn{3}{|c|}{$\begin{array}{c}\text { Input voltage } \\
\text { unbalanced load model A }\end{array}$} & \multicolumn{3}{|c|}{$\begin{array}{c}\text { Output voltage } \\
\text { unbalanced load model A }\end{array}$} & \multicolumn{3}{|c|}{$\begin{array}{c}\text { Input voltage } \\
\text { unbalanced load model B }\end{array}$} & \multicolumn{3}{|c|}{$\begin{array}{c}\text { Output voltage } \\
\text { unbalanced load model B }\end{array}$} \\
\hline & & $\mathrm{R}$ & $\mathrm{S}$ & $\mathrm{T}$ & $\mathrm{R}$ & $\mathrm{S}$ & $\mathrm{T}$ & $\mathrm{R}$ & $\mathrm{S}$ & $\mathrm{T}$ & $\mathrm{R}$ & $\mathrm{S}$ & $\mathrm{T}$ \\
\hline \begin{tabular}{l|} 
Nilai \\
\end{tabular} & Volt & 194,4 & 257,6 & 258,2 & 142,1 & 207,7 & 235,5 & 258,3 & 255,2 & 194,1 & 235,4 & 207,6 & 142,2 \\
\hline sudut & Derajat & 0 & $-111,23$ & 131,08 & 0 & $-149,89$ & 58,9 & 0 & $-115,77$ & 128,88 & 0 & $-153,06$ & 55,33 \\
\hline \multicolumn{2}{|c|}{ Parameter } & \multicolumn{3}{|c|}{$\begin{array}{l}\text { Input current } \\
\text { unbalanced load }\end{array}$} & \multicolumn{3}{|c|}{$\begin{array}{l}\text { Output current } \\
\text { unbalanced load }\end{array}$} & \multicolumn{3}{|c|}{$\begin{array}{l}\text { Input current } \\
\text { unbalanced load }\end{array}$} & \multicolumn{3}{|c|}{$\begin{array}{l}\text { Output current } \\
\text { unbalanced load }\end{array}$} \\
\hline \multicolumn{2}{|c|}{ Fasa } & $\mathrm{R}$ & $\mathrm{S}$ & $\mathrm{T}$ & $\mathrm{R}$ & $\mathrm{S}$ & $\mathrm{T}$ & $\mathrm{R}$ & $\mathrm{S}$ & $\mathrm{T}$ & $\mathrm{R}$ & $\mathrm{S}$ & $\mathrm{T}$ \\
\hline Nilai & Ampere & 0,73 & 0,67 & 0,47 & 0,45 & 0,49 & 0,32 & 0,45 & 0,69 & 0,72 & 0,31 & 0,49 & 0,47 \\
\hline \begin{tabular}{l|} 
sudut \\
\end{tabular} & Derajat & $-15,54$ & $-131,99$ & 105,25 & $-21,43$ & $-173,35$ & 34,84 & $-22,46$ & $-127,12$ & 119,78 & $-20,15$ & $-173,39$ & 32,06 \\
\hline Daya Rata-rata & Watt & 136,71 & 162,57 & 108,82 & 58,89 & 94,3 & 68,67 & 107,43 & 172,65 & 137,99 & 68,51 & 95,39 & 61,4 \\
\hline Losses CU & Watt & 21,84 & 18,68 & 8,99 & 13,97 & 17,02 & 7,11 & 8,30 & 19,52 & 21,25 & 6,78 & 16,69 & 15,40 \\
\hline Total daya & Watt & \multicolumn{3}{|c|}{408,1} & \multicolumn{3}{|c|}{221,86} & \multicolumn{3}{|c|}{418,07} & \multicolumn{3}{|c|}{225,30} \\
\hline Total Losses & Watt & \multicolumn{6}{|c|}{186,24} & \multicolumn{6}{|c|}{192,77} \\
\hline Total losses CU & Watt & \multicolumn{6}{|c|}{87,61} & \multicolumn{6}{|c|}{87,94} \\
\hline Losses besi & Watt & \multicolumn{6}{|c|}{98,63} & \multicolumn{6}{|c|}{104,83} \\
\hline Efisiensi & $\%$ & \multicolumn{6}{|c|}{54,36} & \multicolumn{6}{|c|}{53,89} \\
\hline Daya Semu & VA & 141,89 & 173,85 & 120,89 & 63,26 & 102,79 & 75,20 & 116,24 & 176,09 & 139,75 & 72,97 & 101,72 & 66,83 \\
\hline Cos phi & & 0,96 & 0,94 & 0,90 & 0,93 & 0,92 & 0,91 & 0,92 & 0,98 & 0,99 & 0,94 & 0,94 & 0,92 \\
\hline $\mathrm{Ia} 0$ & Ampere & & & & \multicolumn{3}{|c|}{$0.0662 \angle-11,13^{\circ}$} & & & & \multicolumn{3}{|c|}{$0.0734 \angle 23,07^{\circ}$} \\
\hline Ial & Ampere & & & & \multicolumn{3}{|c|}{$0,382 \angle-49,88^{\circ}$} & & & & \multicolumn{3}{|c|}{$0,3802 \angle-58,25^{\circ}$} \\
\hline Ia2 & Ampere & & & & \multicolumn{3}{|c|}{$0.1771 \angle 52,49^{\circ}$} & & & & \multicolumn{3}{|c|}{$0.1892 \angle 82,88^{\circ}$} \\
\hline IN & Ampere & & & & \multicolumn{3}{|c|}{$0.1986 \angle-11,13^{\circ}$} & & & & \multicolumn{3}{|c|}{$0.2202 \angle 23,07^{\circ}$} \\
\hline $\mathrm{K}$ & $\%$ & & & & & 46,36 & & & & & & 49,76 & \\
\hline
\end{tabular}

Berikut ini merupakan grafik hubungan antara rugi-rugi dengan efisiensi trafo yang dibebani seimbang, tidak seimbang model $A$ dan tidak seimbang model $B$

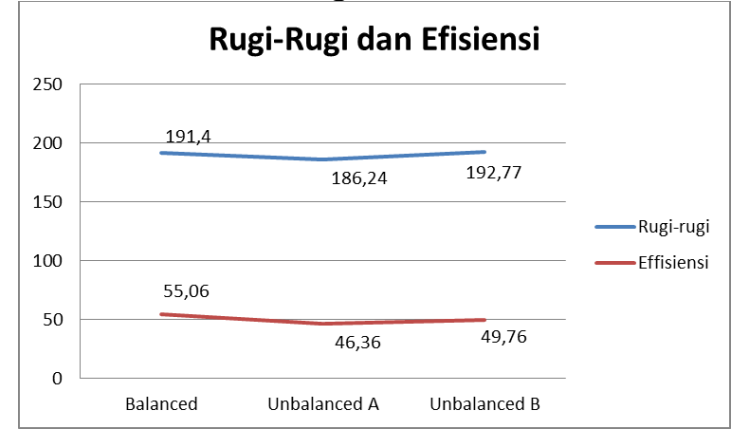

Gambar 6. Grafik rugi-rugi dan efisiensi

Grafik diatas menunjukan bahwa nilai efisiensi akan semakin kecil dengan beban yang tidak seimbang.

Berikut ini merupakan grafik hubungan antara daya primer dan daya sekunder trafo yang dibebani seimbang, tidak seimbang model A dan tidak seimbang model $B$

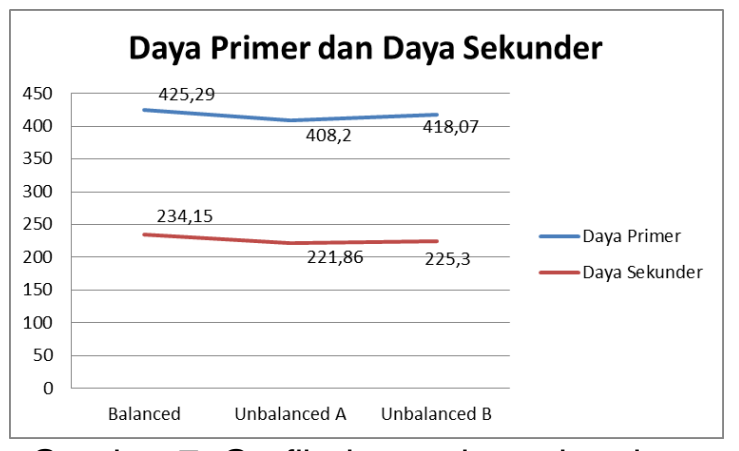

Gambar 7. Grafik daya primer dan daya sekunder

\section{KESIMPULAN}

Kesimpulan yang didapat adalah sebagai berikut:

1. Berdasarkan hasil penelitian menujukan sistem yang telah dibuat dapat digunakan untuk analisis real time rugi-rugi trafo dalam rangka memudahkan dalam memberikan informasi kerugian yang diderita dengan 
visualisasi yang informatif akurat dan dapat dengan mudah diaplikasikan.

2. Dari hasil analisis dapat diketahui bahwa beban tidak seimbang menyebabkan efisiensi trafo semakin kecil dan rugi-rugi dan arus netral semakin besar.

\section{DAFTAR PUSTAKA}

[1] Chapman S.J. Electric Machinery Fundamental, fifthedition McGaw-Hill Book Company. 1985.

[2] W. Chandrasena, P.G. McLaren, U.D. Annakkage, R.P. Jayasinghe, D. Muthumuni, E. Dirks. Simulation of hysteresis and eddy current effects in a power transformer, Electric Power Systems Research 76 (2006) 634-641.

[3] Aoukili,, Abdeslam. Khamlichi, Abdellatif. Damage detection of surface cracks in metallic parts by pulsed Eddy-Current probe. Procedia Manufacturing 22 (2018) 209-214.

[4] Badaruddin, Pengaruh Ketidakseimbangan Beban Terhadap Arus Netral Dan Losses Pada Trafo Distribusi Proyek Rusunami Gading Icon, Universitas Mercu Buana, Jakarta, 2012.

[5] Purwadi, Agus. Heryana, Nana. Nugraha, Febri Arwan. Basharah, Abduh Aziz. Hadisantoso, PC. Didit. Munir, Buyung S. Dakhlan, Abduh Aziz. Testing and Diagnostics of Neutral Earthing Current on 500kV/150 kV Inter Bus Transformer in Tasikmalaya EHV Main Sub Station. Procedia Technology 11 (2013) 980988.

[6] $\mathrm{M}, \quad$ Nagarajam. K,V Kandasamy. Optimal Power Factor Correction For Inductive Load Using PIC. Procedia Engineering 38 (2012) 737-744.

[7] Imran, Tayyab. Hussain, Mukhtar. An overview of LabVIEW-based f-to-2f spectral interferometer for monitoring, data acquiring and stabilizing the slow variations in carrier-envelope phase of amplified femtosecond laser pulses. Optik 157 (2018) 1177-1185. 